The version of record was published by the Disability and Health Journal on 26 November 2019 and is available at [https://doi.org/10.1016/j.dhjo.2019.100872].

\title{
Routine identification of patients with disabilities in primary care: a mixed-methods study
}

Andrew D. Pinto ${ }^{\mathrm{a}, \mathrm{b}, \mathrm{c}, \mathrm{d}}$ (andrew.pinto@utoronto.ca)*

Erica Shenfeld (e.j.shenfeld@gmail.com)

Robert Lattanzio ${ }^{\mathrm{f}}$ (lattanr@lao.on.ca)

Tatiana Aratangyg (aratangyt@smh.ca)

Ri Wangh (wangri1@smh.ca)

Rosane Nisenbaum,g,h (nisenbaumr@smh.ca)

Tara Kiran ${ }^{\text {b,c,g,I }}$ (tara.kiran@utoronto.ca)

a. The Upstream Lab, Centre for Urban Health Solutions, Li Ka Shing Knowledge Institute, St. Michael's Hospital, 30 Bond Street, Toronto, Ontario, Canada, M5B 1W8

b. Department of Family and Community Medicine, St. Michael's Hospital, 30 Bond Street, Toronto, Ontario, Canada, M5B 1W8

c. Department of Family and Community Medicine, Faculty of Medicine, University of Toronto, 500 University Avenue, Toronto, Ontario, Canada, M5G 1V7

d. Dalla Lana School of Public Health, University of Toronto, 155 College Street, Toronto, Ontario, Canada, M5T 3M7

e. Undergraduate Medical Education, Faculty of Medicine, University of Toronto, Toronto, Ontario, Canada, 1 King's College Circle, Toronto, Ontario, Canada, M5S 1A8

f. ARCH Disability Law Centre, 55 University Avenue $-15^{\text {th }}$ Floor, Toronto, Ontario, Canada, M5J $2 \mathrm{H} 7$

g. Centre for Urban Health Solutions, Li Ka Shing Knowledge Institute, St. Michael's Hospital, 30 Bond Street, Toronto, Ontario, Canada, M5B 1W8 
The version of record was published by the Disability and Health Journal on 26 November 2019 and is available at [https://doi.org/10.1016/j.dhjo.2019.100872].

h. Applied Health Research Centre, Li Ka Shing Knowledge Institute, St. Michael's Hospital, 30 Bond Street, Toronto, Ontario, Canada, M5B 1W8

i. Health Quality Ontario, 130 Bloor Street West $-10^{\text {th }}$ Floor, Toronto, Ontario, Canada, M5S 1N5

* Address correspondence to:

Dr. Andrew D. Pinto

St. Michael's Hospital

30 Bond Street

Toronto, Ontario, Canada

M5B 1W8

Tel: $1-416-867-3728$

Fax: 1-416-867-3726

andrew.pinto@utoronto.ca

\section{$\underline{\text { Disclosures }}$}

At the time of writing, Dr. Tara Kiran was the Quality Improvement Program Director and Board Chair for the St. Michael's Hospital Academic Family Health Team. She was also a primary care advisor for the Toronto Central Local Health Integration Network between April 2015 and October 2016.

\section{Funding}


The version of record was published by the Disability and Health Journal on 26 November 2019 and is available at [https://doi.org/10.1016/j.dhjo.2019.100872].

This study was supported by a grant from the Toronto Central Local Health Integration Network. The funder played no role in data collection, data analysis, or the writing and editing of this paper. Drs. Pinto and Kiran are supported as Clinician Scientists by the Department of Family and Community Medicine, Faculty of Medicine at the University of Toronto and at St. Michael's Hospital, and by the Li Ka Shing Knowledge Institute, St. Michael's Hospital. Dr. Pinto is also supported by a fellowship from the Physicians' Services Incorporated Foundation and as the Associate Director for Clinical Research at the University of Toronto Practice-Based Research Network (UTOPIAN). Dr. Kiran is also supported by the Canadian Institutes for Health Research and by Health Quality Ontario as an Embedded Clinician Researcher and is the Fidani Chair in Improvement and Innovation at the University of Toronto. The opinions, results and conclusions reported in this article are those of the authors and are independent from any institution or funding source.

\section{Acknowledgements}

Lisa Miller assisted with extracting data from our electronic medical record and Andree Schuler assisted with data analysis. Cheryl Pedersen, Kimberly Devotta, Paula Smith and Rebecca Brown (Survey Research Unit, Centre for Urban Health Solutions, St. Michael's Hospital) conducted interviews and focus groups and assisted with the qualitative analysis. A number of individuals served on the Advisory Group for this project, including patients, Jane Cooney and Marjeiry Robinson, and representatives Caroline Bennett-AbuAyyash (Mount Sinai Hospital), Cynthia Damba (Toronto Central Local Health Integration Network), Gail Dobell (Health Quality Ontario), Bev Leaver (Stonegate Community Health Centre), Carol Mulder (Association of Family Health Teams of Ontario), Jamie Sample (Association of Family Health Teams of 
The version of record was published by the Disability and Health Journal on 26 November 2019 and is available at [https://doi.org/10.1016/j.dhjo.2019.100872].

Ontario), Bernadee Koh-Bilodeau (Health Quality Ontario), Tomi Nieminen (St. Michael's

Hospital), Cathy O’Neill (St. Michael's Hospital), Erin Pichora (Canadian Institute for Health

Information), and Katherine Henning (University Health Network). Our study findings do not

necessarily represent the views of the Advisory Group, or the position of any organization

represented by members of the Advisory Group.

\section{$\underline{\text { Word count }}$}

Abstract: 250

Body: 2,497

The following manuscript was submitted to the Disability and Health Journal on April 2, 2019 and accepted for publication on November 18, 2019.

The version of record was published by the Disability and Health Journal on November 26th, 2019 and is available at [https://doi.org/10.1016/j.dhjo.2019.100872]. 
The version of record was published by the Disability and Health Journal on 26 November 2019 and is available at [https://doi.org/10.1016/j.dhjo.2019.100872].

Routine identification of patients with disabilities in primary care

\begin{abstract}
$\underline{\text { Abstract }}$
Background

People with disabilities experience barriers to receiving healthcare and often have worse health outcomes, but data on disability is rarely routinely collected in a standardized way.
\end{abstract}

\title{
Objective
}

This study examined how patients responded to being asked about disabilities as part of a routine, self-administered sociodemographic survey.

\section{Methods}

We conducted a mixed-methods study in a multi-site primary care organization. We compared the characteristics of people who responded to a question about disabilities to those who did not respond using logistic regression. We also compared survey responses to data available in medical charts. In-depth interviews were conducted with a sample of patients following survey completion.

\section{Results}

Over 28 months, 15,221 patients were offered the survey and 14,247 (93.6\%) responded to at least one question. Of these, 11,275 (79.1\%) patients answered the question about disabilities. Older patients, patients who rented their home, and non-White patients were less likely to respond to the question. When comparing survey responses to data from medical charts we identified discrepancies. Patients interviewed reported they had difficulty judging what 
The version of record was published by the Disability and Health Journal on 26 November 2019 and is available at [https://doi.org/10.1016/j.dhjo.2019.100872].

\section{Routine identification of patients with disabilities in primary care}

constituted a disability. Stigma related to mental illness and substance use led them to avoid disclosing those conditions.

\section{Conclusions}

Directly asking patients whether they have a disability may be challenging given confusion about what constitutes a disability and stigma associated with certain disabilities. Future research should examine whether asking about barriers faced in accessing health services could adequately identify patients with disabilities and also be used to identify tangible actions an organization could take to lower barriers to care.

Keywords: social determinants of health; primary health care; health services for persons with disabilities; disabled persons; disability evaluation 
The version of record was published by the Disability and Health Journal on 26 November 2019 and is available at [https://doi.org/10.1016/j.dhjo.2019.100872].

\section{Routine identification of patients with disabilities in primary care}

\section{Introduction}

Over one billion people globally experience some form of disability. ${ }^{1}$ People with disabilities and their contexts are heterogenous but certain health disparities are consistent. ${ }^{2}$ People with disabilities have higher rates of cardiovascular disease, diabetes and obesity ${ }^{2,3}$ and report higher rates of chronic pain, sleep disorders and depression than the non-disabled. ${ }^{4}$ They are also at increased risk of injury, violence, and abuse. ${ }^{2}$ People with intellectual disabilities and with severe mental illness are more likely to develop physical illnesses.,

Despite greater health needs, people with disabilities typically experience barriers to healthcare. ${ }^{2}$ They have lower rates of cancer screening, report difficulties accessing primary care, and have lower satisfaction with the healthcare system. ${ }^{7-10}$ Social factors may also contribute to worse health outcomes as people with disabilities are more likely to experience poverty, have lower educational attainment and have reduced access to transportation. ${ }^{2}$ People with disabilities experience discrimination as a result of how other characteristics intersect with their disability. ${ }^{11}$

One obstacle to reducing these inequities is limited data. ${ }^{12,13}$ In the absence of routinely surveying patients, physicians often miss or underestimate disabilities reported by their patients. ${ }^{14}$ In the United States, certain organizations routinely collect data on disability status ${ }^{15}$ but it remains uncommon. ${ }^{12,16}$ Existing research is limited but suggests that patients with and without disabilities appreciate being given the opportunity to describe their disabilities. ${ }^{16}$ 
The version of record was published by the Disability and Health Journal on 26 November 2019 and is available at [https://doi.org/10.1016/j.dhjo.2019.100872].

\section{Routine identification of patients with disabilities in primary care}

Since 2013, our organization has surveyed patients about whether they have disabilities as part of a sociodemographic survey offered to all patients with answers integrated into the electronic medical record (EMR). ${ }^{17}$ The objective of this study was to examine non-response bias, compare patient responses to other data available in the chart, and to understand the experience of patients who responded to the survey. 
The version of record was published by the Disability and Health Journal on 26 November 2019 and is available at [https://doi.org/10.1016/j.dhjo.2019.100872].

Routine identification of patients with disabilities in primary care

\section{$\underline{\text { Methods }}$}

\section{Setting and context}

A sociodemographic survey [APPENDIX 1] for use in a variety of health settings was developed by three academic health science centres and the local public health unit in Toronto, Canada with the support of the regional heath authority. ${ }^{17,18}$ This self-administered survey included a question on disabilities, with options developed based on definitions and categories outlined by the Ontario Human Rights Commission. ${ }^{19}$ In pilot testing the question was stated as 'Do you have any of the following disabilities?'. ${ }^{18}$ Subsequently, the question was stated as 'Do you have any of the following?' [FIGURE 1], with the rationale being that some patients could feel the term 'disability' was stigmatizing or that some patients may not consider a chronic illness as a disability. ${ }^{20}$

In 2013, the survey was implemented at XXXXXXX, a large, primary care organization in XXXXX, Canada. ${ }^{17}$ The organization serves approximately 45,000 patients at six sites. Prior to implementation, clerical staff were oriented to the sociodemographic survey and how to address questions from patients. The survey was routinely offered to all patients on an electronic tablet or on paper when patients arrived for an appointment. Only English versions of the survey were available. Data from electronic tablets was immediately uploaded to the patient's EMR, while data from paper surveys was later entered by staff. A companion could assist with completing the survey if the patient was unable to do so themselves.

\section{Study design}


The version of record was published by the Disability and Health Journal on 26 November 2019 and is available at [https://doi.org/10.1016/j.dhjo.2019.100872].

Routine identification of patients with disabilities in primary care

Details of our methods have been described elsewhere. ${ }^{21}$ In brief, we used a mixed-methods sequential explanatory design. ${ }^{22}$ The quantitative component of the study occurred first, as part of ongoing quality improvement initiatives and was deemed by $\mathbf{X X X X X X}$ to not require formal ethics approval after institutional review. The qualitative component occurred subsequently and was approved by the XXXXXX Research Ethics Board. An advisory group, made up of patients and representatives from local hospitals, the regional health authority and the provincial quality improvement agency, supported this study.

\section{Quantitative data and analysis}

We extracted data from the EMR on patients who were offered the survey between December 1, 2013 and March 31, 2016 and answered at least one question. Data consisted of answers to the sociodemographic survey, age, postal code, health insurance claims and the presence of diagnostic codes. Postal code was used to establish which quintile of average neighbourhood income the patient resided, a common proxy for individual income in Canadian studies. 23, 24, 25 Insurance claims were used to identify patients as living with mental illness or substance use, based on a previously validated methodology. ${ }^{26}$ Existing diagnostic codes in the EMR were used to identify which patients were living with diabetes, HIV and developmental disability. These conditions were identified as priorities by the practice and codes were updated routinely based on a structured search of the EMR and physician validation.

Non-responders were defined as those that selected "prefer not to answer", “don't know", or left the question blank. Since patients could select multiple answers for the disability question, two steps were taken to resolve incompatible responses. If the patient indicated that they had no 
The version of record was published by the Disability and Health Journal on 26 November 2019 and is available at [https://doi.org/10.1016/j.dhjo.2019.100872].

Routine identification of patients with disabilities in primary care

disabilities but still proceeded to select at least one of the disabilities, they were considered to have left the question blank and their disability answers were set as missing. If the patient selected "prefer not to answer" or "do not know" they were recorded as missing or unanswered.

To assess non-response bias, we examined sociodemographic differences between patients who responded (responders) and did not respond (non-responders) to the disability question. We compared age, gender identity, sexual orientation, preferred language, immigration status, race/ethnicity, housing status, mental illness and average neighbourhood income quintile between the groups using chi-square tests for categorical variables and the Mann-Whitney U-test for age (non-normally distributed continuous variable). We pre-specified two-tailed p-values of less than 0.01 as our threshold of a significant difference. Variables that were significantly different between the groups were included in a logistic regression model to estimate adjusted odds ratios (AOR) and 95\% confidence intervals (95\% CI). Anticipating that preferred language, immigration status and race/ethnicity would be highly correlated, a priori we decided to only include race/ethnicity in our regression model. To compare self-reported disability to information in the EMR, we used percentages. We compared self-reported chronic illness to the presence of a diagnostic code for HIV and/or diabetes, self-reported developmental disability to the presence of a diagnostic code for development disability, and self-reported mental illness or drug or alcohol dependence to identification through health insurance claims.

\section{Qualitative data and analysis}

To evaluate the experience of patients in answering a question about disabilities two research staff interviewed a convenience sample of patients immediately after they completed the 
The version of record was published by the Disability and Health Journal on 26 November 2019 and is available at [https://doi.org/10.1016/j.dhjo.2019.100872].

Routine identification of patients with disabilities in primary care

sociodemographic survey. Demographics were collected from patients interviewed and reviewed iteratively to ensure diversity in terms of age and gender representation. Patients were eligible if they were aged 18 or older, could converse in English and had completed the sociodemographic survey that day. Interviews explored the experience of completing the survey, how questions were understood and potential uses and harms of the data collection initiative. Interviews were audio-recorded and transcribed verbatim. Coding was completed in NVivo 11 (QSR International) by a team of five coders. Using the interview guide a small number of codes were created a priori, with further codes emerging from the data. A codebook was created from a subset of interviews, and the remaining data was subsequently coded. After the initial coding was complete a sub-theme analysis of the codes was conducted, and themes were discussed with the entire study team to identify the key findings. 
The version of record was published by the Disability and Health Journal on 26 November 2019 and is available at [https://doi.org/10.1016/j.dhjo.2019.100872].

Routine identification of patients with disabilities in primary care

\section{$\underline{\text { Results }}$}

\section{Quantitative results}

During the 28-month study period, 15,221 patients were offered the survey and 14,247 (93.6\%) responded to at least one question. Of these 11,275 (79.1\%) responded to the question about disabilities. Of those that responded, 6,949 (61.6\%) identified no disabilities, 2,989 (26.5\%) identified one, 915 (8.1\%) identified two, 311 (2.6\%) identified three, and 111 (1.0\%) identified four or more concurrent disabilities. Chronic illness, mental illness, and physical disability were the three most commonly reported disabilities.

Responders to the disability question differed significantly from non-responders with respect to gender, age, spoken language, immigration status, housing status, ethnicity, sexual orientation and average neighbourhood income quintile [TABLE 1], but were similar with respect to the presence of severe mental illness. The odds of responding to the question about disabilities were consistently lower among patients who chose 'prefer not to answer' or 'do not know' or left the question blank for questions about gender identity, housing status, ethnicity, or sexual orientation [TABLE 2]. Adults aged 50-59 years (AOR: 0.81 (95\% CI 0.70-0.93), p=0.0039) and aged 70 years and older (AOR: 0.78 (95\% CI 0.65-0.94), $\mathrm{p}=0.0071)$ had lower odds of responding to the question on disabilities when compared to individuals aged 30-39 years. People who rented had lower odds of responding than those who owned their home (AOR: 0.79 (95\% CI 0.70-0.88), $\mathrm{p}<0.0001)$. Patients who identified as non-White had lower odds of responding compared to individuals who were White (AOR: 0.69 (95\% CI 0.63-0.77), $\mathrm{p}<0.0001)$. In our adjusted analysis, neighbourhood income quintile was not significantly associated with responding. 
The version of record was published by the Disability and Health Journal on 26 November 2019 and is available at [https://doi.org/10.1016/j.dhjo.2019.100872].

Routine identification of patients with disabilities in primary care

When we compared self-reported disabilities to other data in the EMR we found that patients may have chosen not to disclose a disability. Of those who had had a record of a mental healthrelated visit, 76.8\% did not report that they had a mental illness on the survey. Of those who had had a visit for psychotic disorders, 38.2\% did not report that they had a mental illness on the survey. Of those who had had a record of a visit related to substance use, $62.2 \%$ did not report that they had drug or alcohol dependence issues on the survey. Of those with diabetes or HIV based on their medical chart, $60.5 \%$ reported that they did not have a chronic illness on the survey.

\section{Qualitative findings}

We interviewed a diverse group of 27 patients [APPENDIX 2]. Our interviews with patients revealed two key themes. First, patients reported difficulty in judging whether a condition they had fit the options provided in the question, several which used the term "disability". Patients felt that simply having been diagnosed with a condition did not equate with living with a disability if they were currently not experiencing impairment. One participant reported, "I have some vision loss ... I have macular degeneration so like I am not driving... I wasn't sure whether you'd consider that a disability because I'm not blind." The options 'chronic illness', 'mental illness' and 'drug and alcohol dependence' caused the greatest confusion, reflecting the fluctuating nature of symptoms and behavior. One patient stated, "I don't know what they mean by chronic illness ... something that's going to kill you or just something that you're going to have for all the rest of your life." Another participant, when discussing choosing the option "mental illness" noted, "I don't want to be like labeled with it like for the rest of my life... if it's temporary". 
Another participant noted, "I know that I have ... certain ... mental disabilities and stuff - but ... I've never [been] diagnosed with anything ... so I can't say exactly what I have." These findings fit with our quantitative results that found a discrepancy between medical diagnoses and patient self-reported disabilities.

Second, patients reported concerns about the stigma associated with self-identifying mental illness and drug and alcohol dependence. One patient noted, "when you say 'mental illness', I think that's a whole bag of things ... people [are] ... a little bit less likely to want to admit that kind of things. There's a stigma attached.”. Another patient noted, “...Definitely mental illness and drug or alcohol dependence [were stigmatizing]. I think that although like it is a problem it's a ... bit weird to like, kind of admit that or like circle it". These findings fit with our quantitative results that found that many patients with a medical visit for mental illness or substance use did not self-identity as having these conditions. 
The version of record was published by the Disability and Health Journal on 26 November 2019 and is available at [https://doi.org/10.1016/j.dhjo.2019.100872].

Routine identification of patients with disabilities in primary care

\section{$\underline{\text { Discussion }}$}

We studied the experience of patients in a multi-site primary care organization who were asked to self-report on disability as part of a routine sociodemographic survey. We found that most patients responded to the question about disability. Non-responders were more likely to have not responded to other questions on the survey and tended to be older, non-White, and rent their home. We found a discrepancy between answers on the survey to information in the chart. Through interviews we found that patients were not sure whether their health conditions fit into the options provided, particularly those that were identified as a disability. Many patients were concerned about stigma related to mental illness and drug and alcohol dependence.

The strengths of this study include our pragmatic implementation of the survey, our large sample on which to base our quantitative findings, and our mix of quantitative and qualitative methods. Limitations of this study include that it reports on a single institution, albeit one that consists of multiple clinic sites serving a diverse population. Another limitation is that patients who were interviewed were not stratified into those with and without disabilities. We also do not know how many surveys were completed by a caregiver rather than the patient. Finally, data in the EMR may not always be correct, and hence may not be an appropriate gold standard for the presence or absence of a disability.

Our findings fit with other published work. A study of 303 patients surveyed in three out-patient clinics found $77 \%$ were comfortable with healthcare organizations collecting data on disabilities $^{16}$, a proportion similar to the proportion that responded in our study. In our study, of 
The version of record was published by the Disability and Health Journal on 26 November 2019 and is available at [https://doi.org/10.1016/j.dhjo.2019.100872].

Routine identification of patients with disabilities in primary care

those who responded, almost $40 \%$ identified at least one disability. This is a higher proportion than a study conducted of 128,636 new outpatients at Mayo Clinic, Rochester, MN who were surveyed using the question 'Are you disabled?' where $11.6 \%$ responded 'yes' ${ }^{27}$ The difference is most likely as a result of how our question was worded. We found evidence of possible underreporting of certain conditions, likely as patients did not consider these conditions as a disability particularly if the disease was under good control (e.g. HIV infection or diabetes), or felt stigma around reporting a condition (e.g. substance use).

An alternative approach would frame disability as it relates to how people experience their context rather than as a medical condition. Future research could examine barriers faced to accessing health care and other necessary services. This would be less stigmatizing, clarify the purpose of the question, and answers would be actionable by health organizations. For example, health organizations could use this data to introduce accommodations for specific patients. A starting point could be questions developed by Morris et al. based on the US Department of Health and Human Services recommended questions that ask patients about disabilities related to hearing, vision, motor function, cognitive ability, communication, learning and the ability to conduct activities of daily living. ${ }^{28}$ 
The version of record was published by the Disability and Health Journal on 26 November 2019 and is available at [https://doi.org/10.1016/j.dhjo.2019.100872].

Routine identification of patients with disabilities in primary care

\section{$\underline{\text { Conclusion }}$}

Our study helps advance our understanding of how patients respond to being surveyed about disabilities. ${ }^{29}$ While data collection has been identified as a key part of improving health of people with disabilities ${ }^{30}$ it remains uncommon. Routinely collecting data on accessibility could help providers identify accommodations that are needed to improve access, could make care plans more patient-centred, and when aggregated, could be used to proactively identify issues with access and health disparities. ${ }^{19,19}$ 
The version of record was published by the Disability and Health Journal on 26 November 2019 and is available at [https://doi.org/10.1016/j.dhjo.2019.100872].

Routine identification of patients with disabilities in primary care

\section{$\underline{\text { References }}$}

1. $\quad$ World Health Organization. World Report on Disability. Vol 105.; 2012. doi:10.1016/S0140-6736(11)60844-1.

2. Krahn GL, Walker DK, Correa-De-Araujo R. Persons with disabilities as an unrecognized health disparity population. Am J Public Health. 2015;105:S198-S206. doi:10.2105/AJPH.2014.302182.

3. Wisdom JP, McGee MG, Horner-Johnson W, Michael YL, Adams E, Berlin M. Health disparities between women with and without disabilities: a review of the research. Soc Work Public Health. 2010;25(3):368-386. doi:10.1080/19371910903240969.

4. Kinne S, Patrick DL, Doyle DL. Prevalence of Secondary Conditions among People with Disabilities. Am J Public Health. 2004;94(3):443-445. doi:10.2105/AJPH.94.3.443.

5. Ouellette-Kuntz H. Understanding health disparities and inequities faced by individuals with Intellectual Disabilities. J Appl Res Intellect Disabil. 2005;(18):113-121. doi:10.1111/j.1468-3148.2005.00240.x.

6. De Hert M, Correll CU, Bobes J, et al. Physical illness in patients with severe mental disorders. I. Prevalence, impact of medications and disparities in health care. World Psychiatry. 2011;10(1):52-77. doi:10.1002/j.2051-5545.2011.tb00014.x.

7. Lofters A, Guilcher S, Glazier RH, Jaglal S, Voth J, Bayoumi AM. Screening for cervical cancer in women with disability and multimorbidity: a retrospective cohort study in Ontario, Canada. C open. 2014;2(4):E240-7. doi:10.9778/cmajo.20140003.

8. Veltman A, Stewart DE, Tardif GS, Branigan M. Perceptions of primary healthcare services among people with physical disabilities - part 1: access issues. MedGenMed. 
The version of record was published by the Disability and Health Journal on 26 November 2019 and is available at [https://doi.org/10.1016/j.dhjo.2019.100872].

Routine identification of patients with disabilities in primary care

2001;3(2):18.

9. Casey R. Disability and unmet health care needs in Canada: A longitudinal analysis.

Disabil Health J. 2015;8(2):173-181. doi:10.1016/j.dhjo.2014.09.010.

10. Fouts BS, Andersen E, Hagglund K. Disability and satisfaction with access to care. $J$ Epidemiol Community Heal. 2000;54:770-771. doi:10.1136/jech.54.10.770.

11. Ontario Human Rights Commission. Policy on Abelism and Discrimination Based on Disability.; 2016. http://www.ohrc.on.ca/en/policy-ableism-and-discrimination-baseddisability.

12. Iezzoni LI. Tracking disability disparities: the data dilemma. J Health Serv Res Policy. 2008;13(3):129-130. doi:10.1258/jhsrp.2008.008034.

13. Mitra S. A data revolution for disability-inclusive development. Lancet Glob Heal. 2013;1(4):e178-e179. doi:10.1016/S2214-109X(13)70016-0.

14. Calkins DR, Rubenstein L V, Cleary PD, et al. Failure of physicians to recognize functional disability in ambulatory patients. Ann Intern Med. 1991;114:451-454.

15. Pendo E. Collecting New Data on Disability Health Inequities. Hastings Cent Rep. 2016;46(2):7-8. doi:10.1002/hast.540.

16. Morris MA, Schliep M, Liesinger J, Cameron KA. Collection of Patients ' Disability Status by Healthcare Organizations : Patients' Perceptions and Attitudes. J Healthc Qual. 2017;39(4):219-229.

17. XXXXX, XXXXXX. J Am Board Fam Med. XXXXXX

18. Toronto Public Health, St. Michael's, CAMH, Mount Sinai Hospital. We Ask Because We Care: The Tri-Hospital + TPH Health Equity Data Collection Research Project Report. Toronto; 2013. 
The version of record was published by the Disability and Health Journal on 26 November 2019 and is available at [https://doi.org/10.1016/j.dhjo.2019.100872].

Routine identification of patients with disabilities in primary care

19. Ontario Human Rights Commission. Count me in! Collecting human rights-based data | Ontario Human Rights Commission. OHRC Website. http://www.ohrc.on.ca/en/count-mecollecting-human-rights-based-data. Published 2009.

20. Bennett-Abuayyash C. RE : Quick question about disabilities in HEQ. Personal Communication: July 19, 2018.

21. XXXXXX. Can Med Assoc J. XXXXX.

22. Ivankova N V., Creswell JW, Stick SL. Using Mixed-Methods Sequential Explanatory Design: From Theory to Practice. Field methods. 2006;18(1):3-20. doi:10.1177/1525822X05282260.

23. Glazier RH, Agha MM, Moineddin R, Sibley LM. Universal health insurance and equity in primary care and specialist office visits: A population-based study. Ann Fam Med. 2009;7(5):396-405. doi:10.1370/afm.994.

24. Glazier RH, Klein-Geltink J, Kopp A, Sibley LM. Capitation and enhanced fee-for-service models for primary care reform: A population-based evaluation. Can Med Assoc J. 2009;180(11):72-81. doi:10.1503/cmaj.081316.

25. Glazier RH, Kopp A, Schultz SE, Kiran T, Henry DA. All the Right Intentions but Few of the Desired Results: Lessons on Access to Primary Care from Ontario’s Patient Enrolment Models. Healthc Q. 2012;15(3):17-21.

26. Steele LSLS, Glazier RHRH, Lin EE, Evans MM. Using administrative data to measure ambulatory mental health service provision in primary care. Med Care. 2004;42(10):960965. doi:10.1097/00005650-200410000-00004.

27. Morris MA, Inselman J, Rogers JMG, Halverson C, Branda M, Griffin JM. How do patients describe their disabilities? A coding system for categorizing patients' 
The version of record was published by the Disability and Health Journal on 26 November 2019 and is available at [https://doi.org/10.1016/j.dhjo.2019.100872].

Routine identification of patients with disabilities in primary care

descriptions. Disabil Health J. 2018;11(2):310-314. doi:10.1016/j.dhjo.2017.10.006.

28. Morris MA, Lagu T, Maragh-Bass A, Liesinger J, Griffin JM. Development of PatientCentered Disability Status Questions to Address Equity in Care. Jt Comm J Qual Patient Saf. 2017;43(12):642-650. doi:10.1016/j.jcjq.2017.06.011.

29. Morris MA, Hasnain-Wynia R. A research agenda for documenting disability status within healthcare organizations to address disparities in care. J Healthc Qual. 2014;36(2):7-3. doi:10.1111/jhq.12059.

30. World Health Organization. WHO Global Disability Action Plan 2014-2021.; 2014. 
The version of record was published by the Disability and Health Journal on 26 November 2019 and is available at [https://doi.org/10.1016/j.dhjo.2019.100872].

Routine identification of patients with disabilities in primary care

Figure legends

Figure 1: Question used to routinely ask patients to self-identify disabilities. 
The version of record was published by the Disability and Health Journal on 26 November 2019 and is available at [https://doi.org/10.1016/j.dhjo.2019.100872].

Routine identification of patients with disabilities in primary care

Table 1: Sociodemographic characteristics of patients who responded to the question on disabilities compared to non-responders

\begin{tabular}{|c|c|c|c|}
\hline & $\begin{array}{l}\text { Responders } \\
\mathbf{n}=11275\end{array}$ & $\begin{array}{l}\text { Non-responders } \\
\mathbf{n}=2972\end{array}$ & P-value \\
\hline Gender & & & $<0.0001$ \\
\hline Male* & 4599 (40.8\%) & $1088(36.6 \%)$ & \\
\hline Female & $6396(56.7 \%)$ & 1475 (49.6\%) & \\
\hline Other** & 99 (0.9\%) & $29(1.0 \%)$ & \\
\hline $\begin{array}{r}\text { Prefer Not to } \\
\text { Answer/Do Not } \\
\text { Know/Missing }\end{array}$ & $181(1.6 \%)$ & $380(12.8 \%)$ & \\
\hline Age & & & 0.0094 \\
\hline$<10$ years old & $156(1.4 \%)$ & $41(1.4 \%)$ & \\
\hline 10-19 years & $162(1.4 \%)$ & $41(1.4 \%)$ & \\
\hline 20-29 years & 1536 (13.6\%) & 383 (12.9\%) & \\
\hline 30-39 years & 2806 (24.9\%) & 655 (22.0\%) & \\
\hline $40-49$ years & 2165 (19.2\%) & $570(19.2 \%)$ & \\
\hline 50-59 years & 2032 (18.0\%) & 573 (19.3\%) & \\
\hline 60-69 years & $1422(12.6 \%)$ & 399 (13.4\%) & \\
\hline $70+$ years & 996 (8.8\%) & $310(10.4 \%)$ & \\
\hline Median (IQR) & $44(33-57)$ & $46(34-59)$ & 0.0003 \\
\hline Language [spoken] & & & $<0.0001$ \\
\hline
\end{tabular}


The version of record was published by the Disability and Health Journal on 26 November 2019 and is available at [https://doi.org/10.1016/j.dhjo.2019.100872].

Routine identification of patients with disabilities in primary care

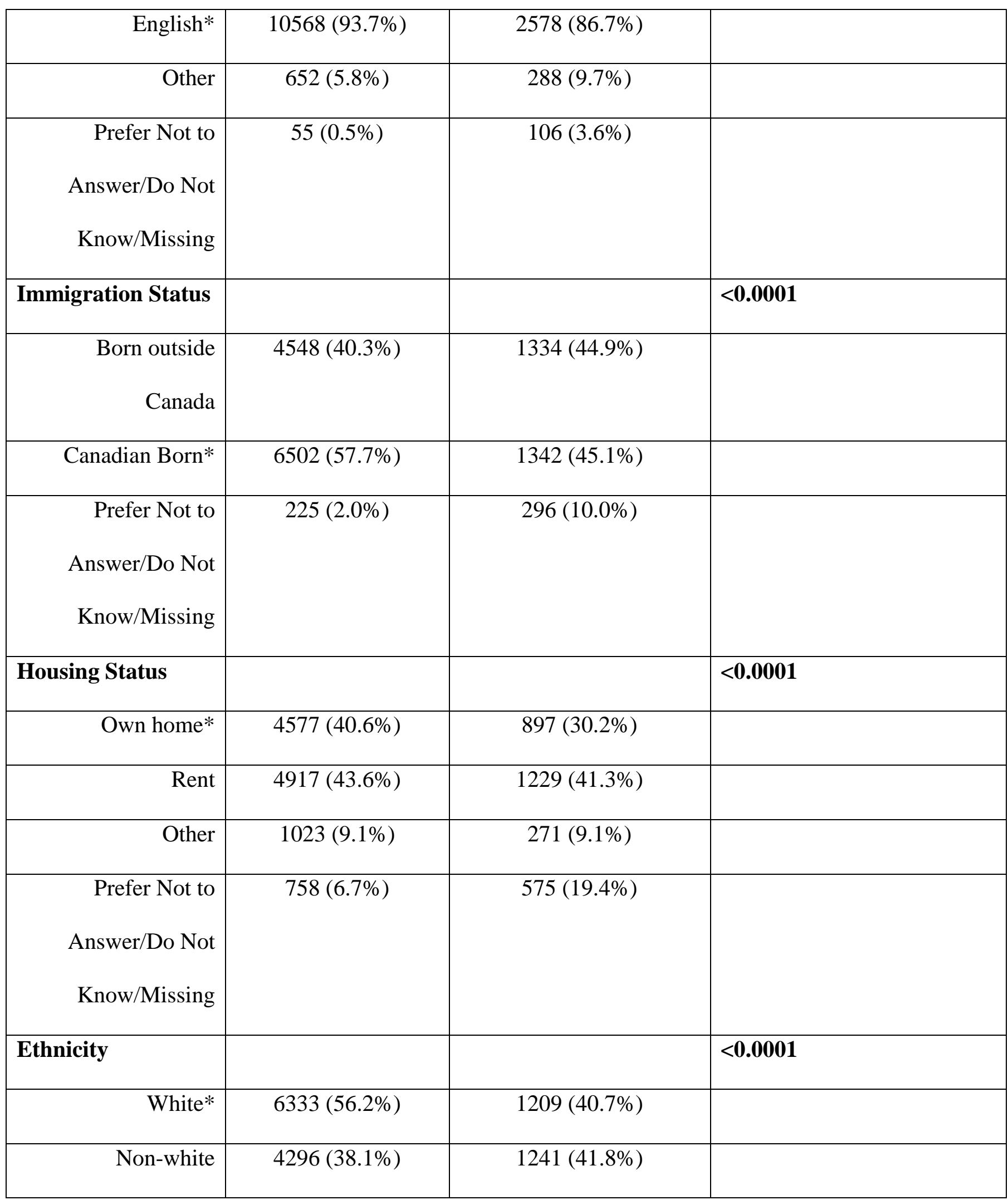


The version of record was published by the Disability and Health Journal on 26 November 2019 and is available at [https://doi.org/10.1016/j.dhjo.2019.100872].

Routine identification of patients with disabilities in primary care

\begin{tabular}{|c|c|c|c|}
\hline $\begin{array}{r}\text { Prefer Not to } \\
\text { Answer/Do Not } \\
\text { Know/Missing }\end{array}$ & $646(5.7 \%)$ & $522(17.6 \%)$ & \\
\hline Sexual Orientation & & & $<0.0001$ \\
\hline Heterosexual* & 8829 (78.3\%) & 1955 (65.8\%) & \\
\hline $\begin{array}{c}\text { Gay/Bisexual } \\
\text { /Lesbian /Queer } \\
\text { /Two-Spirit /Other }\end{array}$ & 1757 (15.6\%) & 365 (12.3\%) & \\
\hline $\begin{array}{r}\text { Prefer Not to } \\
\text { Answer/Do Not } \\
\text { Know/Missing }\end{array}$ & $689(6.1 \%)$ & $652(21.9 \%)$ & \\
\hline Mental health & & & 0.8454 \\
\hline $\begin{array}{r}\text { Severe mental } \\
\text { illness*** }\end{array}$ & $321(2.8 \%)$ & $82(2.8 \%$ & \\
\hline $\begin{array}{l}\text { Neighbourhood } \\
\text { Income Quintile }\end{array}$ & & & $<0.0001$ \\
\hline Q1 & $2690(28.2 \%)$ & $820(33.0 \%)$ & \\
\hline Q2 & 1578 (16.5\%) & $423(17.0 \%)$ & \\
\hline Q3 & 1481 (15.5\%) & $391(15.8 \%)$ & \\
\hline Q4 & $1493(15.6 \%)$ & $323(13.0 \%)$ & \\
\hline Q5 & 2307 (24.2\%) & $524(21.1 \%)$ & \\
\hline
\end{tabular}

${ }^{*} \chi^{2}$ for categorical, Mann-Whitney U-Test for Continuous Age 
The version of record was published by the Disability and Health Journal on 26 November 2019 and is available at [https://doi.org/10.1016/j.dhjo.2019.100872].

Routine identification of patients with disabilities in primary care

** Includes trans-FTM, trans-MTF, intersex, “other”, and those who selected multiple gender terms

*** Includes patients with a bill submitted that includes the diagnostic code for schizophrenia, bipolar disorder, psychosis, paranoia or psychosis not otherwise specified 
The version of record was published by the Disability and Health Journal on 26 November 2019

and is available at [https://doi.org/10.1016/j.dhjo.2019.100872].

Routine identification of patients with disabilities in primary care

Table 2: Adjusted odds ratios and 95\% confidence intervals for the association between responding to a question about

disabilities and socioeconomic variables

\begin{tabular}{|c|c|c|c|}
\hline Covariate & & AOR (95\% CI) & P-Value \\
\hline \multirow[t]{4}{*}{ Gender } & Female & $1.08(0.97-1.19)$ & 0.1537 \\
\hline & Other (Intersex/Transgender/Other) & $0.77(0.47-1.26)$ & 0.3063 \\
\hline & Prefer Not to Answer/Do Not Know/Missing & $0.28(0.22-0.35)$ & $<0.0001$ \\
\hline & Male (reference) & & \\
\hline \multirow[t]{7}{*}{ Age } & $<10$ years old vs. $30-39$ years old & $1.58(1.04-2.40)$ & 0.0308 \\
\hline & $10-19$ years vs. $30-39$ years old & $1.13(0.74-1.72)$ & 0.5809 \\
\hline & 20-29 years vs. 30-39 years old & $0.99(0.84-1.17)$ & 0.9271 \\
\hline & 40-49 years vs. $30-39$ years old & $0.87(0.75-1.01)$ & 0.0659 \\
\hline & 50-59 years vs. 30-39 years old & $0.81(0.70-0.93)$ & 0.0039 \\
\hline & 60-69 years vs. 30-39 years old & $0.82(0.69-0.96)$ & 0.0158 \\
\hline & $70+$ years vs. $30-39$ years old & $0.78(0.65-0.94)$ & 0.0071 \\
\hline \multirow[t]{3}{*}{ Housing status } & Renting vs. Own home & $0.79(0.70-0.88)$ & $<0.0001$ \\
\hline & Other vs. Own home & $0.87(0.73-1.04)$ & 0.1276 \\
\hline & Prefer Not to Answer/Do Not Know/Missing vs. Own home & $0.51(0.43-0.61)$ & $<0.0001$ \\
\hline Ethnicity & Non-White vs. White & $0.69(0.63-0.77)$ & $<0.0001$ \\
\hline
\end{tabular}


The version of record was published by the Disability and Health Journal on 26 November 2019 and is available at [https://doi.org/10.1016/j.dhjo.2019.100872].

\section{Routine identification of patients with disabilities in primary care}

\begin{tabular}{|l|l|l|l|}
\hline & Prefer Not to Answer/Do Not Know/Missing vs. White & $0.5(0.42-0.59)$ & $<\mathbf{0 . 0 0 0 1}$ \\
\hline & & & \\
\hline Sexual orientation & Gay/Bisexual /Lesbian /Queer /Two-Spirit/Other & $1.06(0.92-1.22)$ & 0.4402 \\
\hline & Prefer Not to Answer/Do Not Know/Missing vs. Heterosexual & $0.42(0.36-0.49)$ & $<\mathbf{0 . 0 0 0 1}$ \\
\hline & & & \\
\hline Average neighbourhood income quintile* & Q2 vs. Q1 & $1.03(0.89-1.18)$ & 0.7111 \\
\hline & Q3 vs. Q1 & $1.01(0.87-1.16)$ & 0.9321 \\
\hline & Q4 vs. Q1 & $1.11(0.95-1.29)$ & 0.1971 \\
\hline & Q5 vs. Q1 & $1.04(0.91-1.19)$ & 0.5757 \\
\hline
\end{tabular}

*Q1 is the lowest average neighbourhood income quintile, and Q5 is the highest average neighbourhood income quintile. 